\title{
Proteomic analysis reveals differential accumulation of small heat shock proteins and late embryogenesis abundant proteins between ABA-deficient mutant vp5 seeds and wild-type Vp5 seeds in maize
}

\author{
Xiaolin Wu ${ }^{\dagger}$, Fangping Gong ${ }^{\dagger}$, Le Yang, Xiuli Hu, Fuju Tai and Wei Wang * \\ State Key Laboratory of Wheat and Maize Crop Science, Collaborative Innovation Center of Henan Grain Crops, College of Life Science, Henan Agricultural \\ University, Zhengzhou, China
}

\section{Edited by:}

Silvia Mazzuca, Università della

Calabria, Italy

Reviewed by:

Myriam Ferro, Commisariat à

I'Energie Atomique et aux Energies

Alternatives, France

Loïc Rajjou, AgroParisTech - Paris

Institute of Technology for Life, Food

and Environmental Sciences, France

*Correspondence:

Wei Wang, Collaborative Innovation Center of Henan Grain Crops,

College of Life Science, Henan Agricultural University, 63 Nongye

Road, Zhengzhou 450002, China

e-mail:wangwei@henau.edu.cn

these authors have contributed equally to this work.
ABA is a major plant hormone that plays important roles during many phases of plant life cycle, including seed development, maturity and dormancy, and especially the acquisition of desiccation tolerance. Understanding of the molecular basis of ABA-mediated plant response to stress is of interest not only in basic research on plant adaptation but also in applied research on plant productivity. Maize mutant viviparous-5 (vp5), deficient in ABA biosynthesis in seeds, is a useful material for studying ABA-mediated response in maize. Due to carotenoid deficiency, vp5 endosperm is white, compared to yellow Vp5 endosperm. However, the background difference at proteome level between vp5 and $V p 5$ seeds is unclear. This study aimed to characterize proteome alterations of maize vp5 seeds and to identify ABA-dependent proteins during seed maturation. We compared the embryo and endosperm proteomes of $v p 5$ and $V p 5$ seeds by gel-based proteomics. Up to 46 protein spots, most in embryos, were found to be differentially accumulated between vp5 and Vp5. The identified proteins included small heat shock proteins (sHSPs), late embryogenesis abundant (LEA) proteins, stress proteins, storage proteins and enzymes among others. However, EMB564, the most abundant LEA protein in maize embryo, accumulated in comparable levels between vp5 and Vp5 embryos, which contrasted to previously characterized, greatly lowered expression of emb564 mRNA in vp5 embryos. Moreover, LEA proteins and sHSPs displayed differential accumulations in vp5 embryos: six out of eight identified LEA proteins decreased while nine sHSPs increased in abundance. Finally, we discussed the possible causes of global proteome alterations, especially the observed differential accumulation of identified LEA proteins and sHSPs in vp5 embryos. The data derived from this study provides new insight into ABA-dependent proteins and ABA-mediated response during maize seed maturation.

Keywords: abscisic acid (ABA), late embryogenesis abundant proteins (LEA proteins), maize ABA-deficient mutant vp5, mass spectrometry, protein abundance, proteome profiling, small heat shock proteins (sHSPs), 2-D electrophoresis (2-DE)

\section{INTRODUCTION}

Abscisic acid (ABA) is a major hormone that regulates a broad range of plant traits and is especially important for plant adaptation to environmental conditions. In seeds, $A B A$ is thought to play a central role in many developmental stages, such as seed maturation and dormancy, the accumulation of nutritive reserves and the acquisition of desiccation tolerance (Quatrano, 1986). ABA-mediated plant response to stress has been extensively studied in different species ranging from Arabidopsis to crops, especially regarding ABA sensing, signaling, metabolism and transport (Umezawa et al., 2010). Knowledge about the complexity of ABA-mediated plant response to stress is still full of gaps, but the recent identification of ABA receptors (Ma et al., 2009; Santiago et al., 2009) and the key factors of the first step of ABA signal transduction (Park et al., 2009; Nishimura et al.,
2010) in Arabidopsis provided an important insight into this mechanism.

Biosynthesis of $\mathrm{ABA}$ has been well characterized in Arabidopsis (Zeevaart and Creelman, 1988) and some data is available for other species, such as maize (Tan et al., 1997). Maize, viviparous-5 ( $v p 5$ ) is deficient in ABA biosynthesis with the first step catalyzed by phytoene desaturase being blocked, which results in the precursor phytoene accumulation and carotenoid deficiency (Robichaud et al., 1980; Hable et al., 1998). Previous studies reported that $\mathrm{ABA}$ content in $v p 5$ embryos and endosperms was substantially reduced to 10 and $42 \%$ of the corresponding wild-type, respectively (Neill et al., 1986). The $v p 5$ seeds exhibit a visible phenotypic difference: the endosperm of mutant $v p 5$ seeds was white, while that of wild-type $V p 5$ seeds was yellow. Therefore, $v p 5$ mutant is particularly useful not only 
for studies on the regulation of ABA-dependent maize genes, both in embryo and vegetative tissues, but also for studies of embryo development, seed germination and dormancy (Pla et al., 1989; Durantini et al., 2008).

Up to date, the expression of many individual gene/proteins has been studied using ABA-deficient mutant maize $v p 5$ and wild-type Vp5 (Pla et al., 1989; Thomann et al., 1992). Williams and Tsang (1991) found emb564 mRNA is expressed at low level in $v p 5$ embryos. The level of 3-hydroxy-3-methylglutaryl coenzyme A reductase activity, a rate-limiting enzyme of isoprenoid biosynthesis, is higher in $v p 5$ endosperm (Moore and Oishi, 1994). Recently, we compared root and leaf proteome differences between $v p 5$ and $V p 5$ seedlings with 2-D gel electrophoresis (2-DE) combined mass spectrometry (MS/MS) and found that many proteins accumulation in roots or leaves are differentially regulated by drought and light in an ABA-dependent way ( $\mathrm{Hu}$ et al., 2011, 2012). However, protein accumulation alterations caused by ABA-deficient mutation in $v p 5$ seeds are unclear at a proteome scale. Therefore, the characterization of seed proteome difference between $v p 5$ and $V p 5$ is necessary for dissection of ABA-mediated maize response in the studies involved $v p 5$ mutants.

2-DE-based proteomics approach provides a powerful tool to analyze the expression levels of proteins, distinguish varieties and genotypes and even to identify single mutations with multiple effects (Lehesranta et al., 2005). This study aimed to characterize proteome alterations due to ABA-deficient mutation and further to identify ABA-dependent protein accumulation during seed maturation. We found significant proteome differences between $v p 5$ and $V p 5$ seeds, where 46 differentially accumulated proteins were successfully identified. Most notably, six out of eight late embryogenesis abundant (LEA) proteins and nine small heat shock proteins (sHSPs) were found to differentially accumulate in ABA-deficient $v p 5$ embryos: six identified LEA proteins were repressed while nine sHSPs were induced.

\section{MATERIALS AND METHODS PLANT MATERIALS}

Maize (Zea mays L.) ABA-deficient mutant $v p 5$ mutant was provided by Maize Genetics Cooperation Stock Center (Urbana,
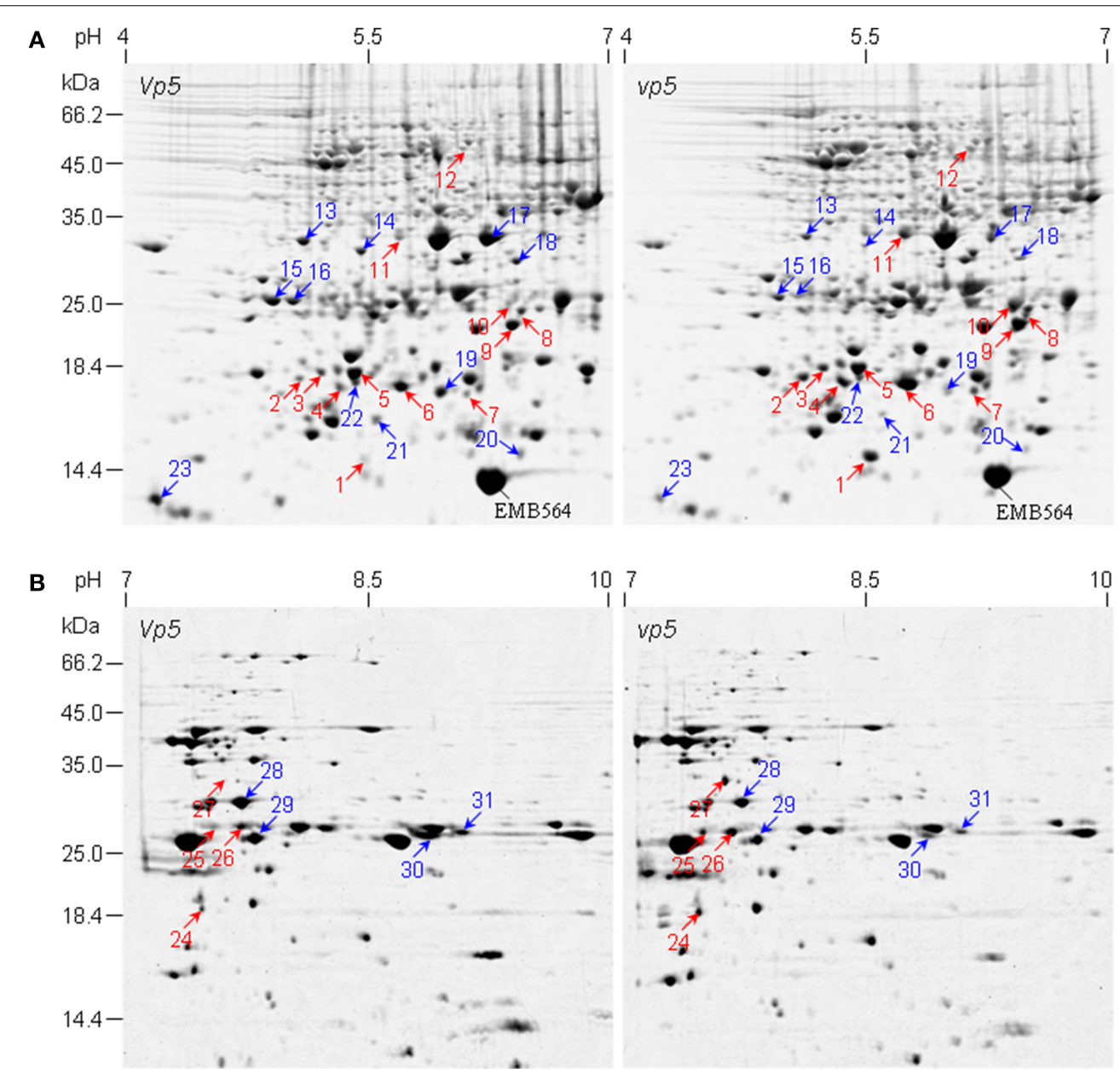

FIGURE 1 | 2-DE comparison of embryo protein profiles between maize mutant $\boldsymbol{v p 5}$ and wild type $\boldsymbol{V p 5}$. (A,B) are representative 2-DE gels of $\mathrm{pH}$ 4-7 and $\mathrm{pH} 7-10$, respectively. Differentially accumulated protein spots between vp5 and Vp5 embryos are indicated by arrows. Red arrow, increased abundance in vp5; blue arrow, increased abundance in Vp5. Embryo protein was extracted and resolved in 2-DE with IEF in the first dimension and $13.5 \%$ SDS-PAGE gel in the second dimension. Gels were stained with colloidal CBB G250. The identified proteins were listed in Tables 1, 2. 


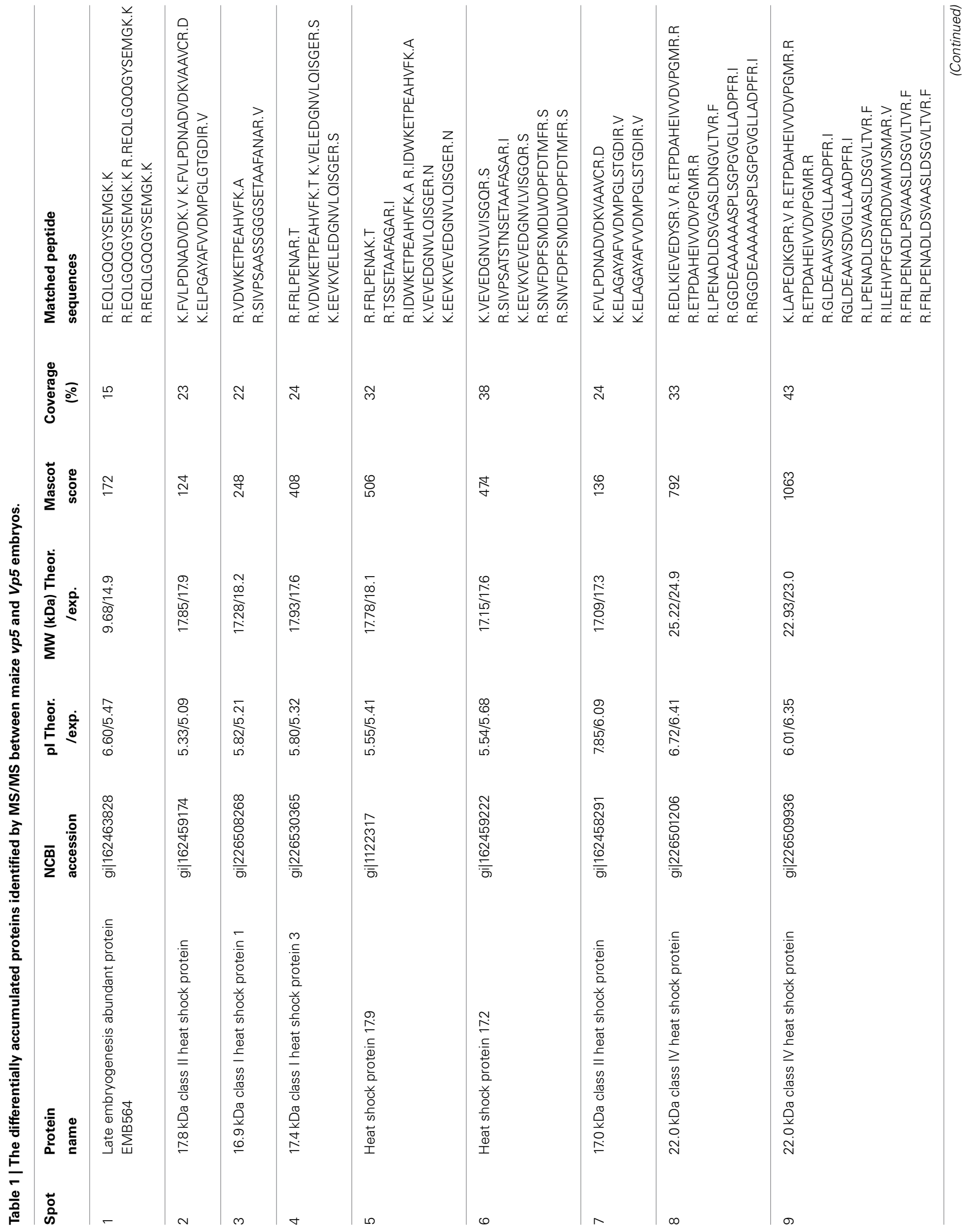




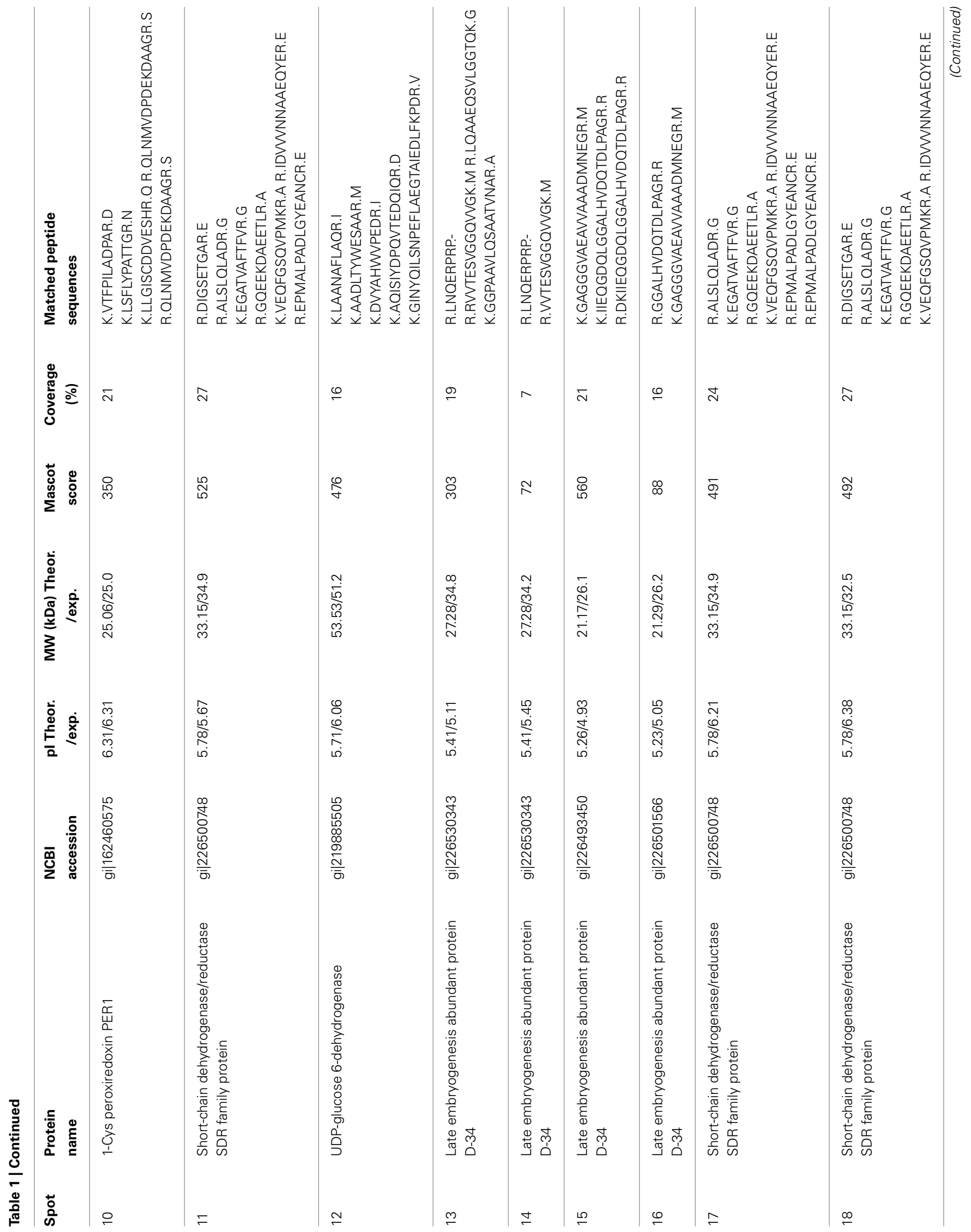




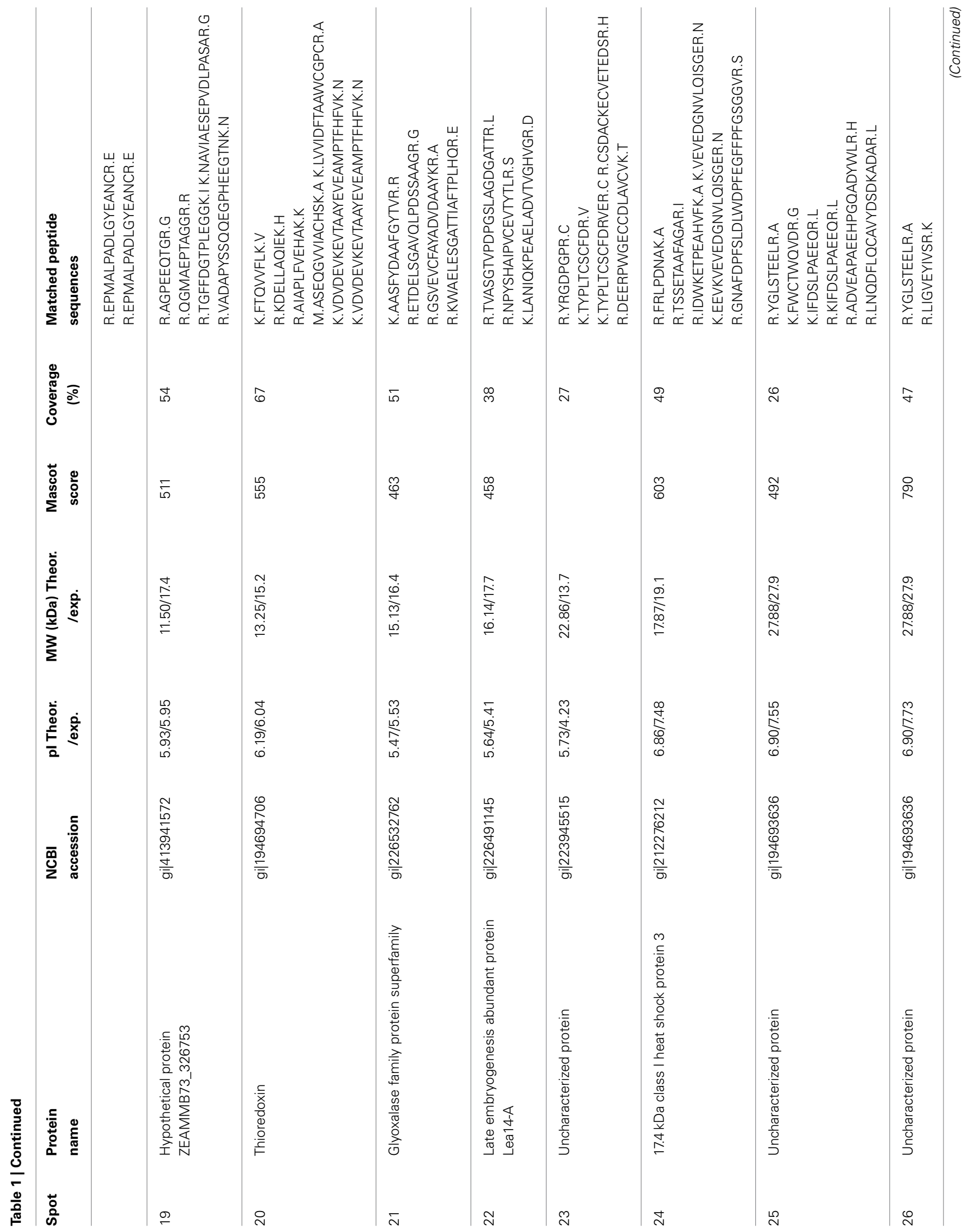




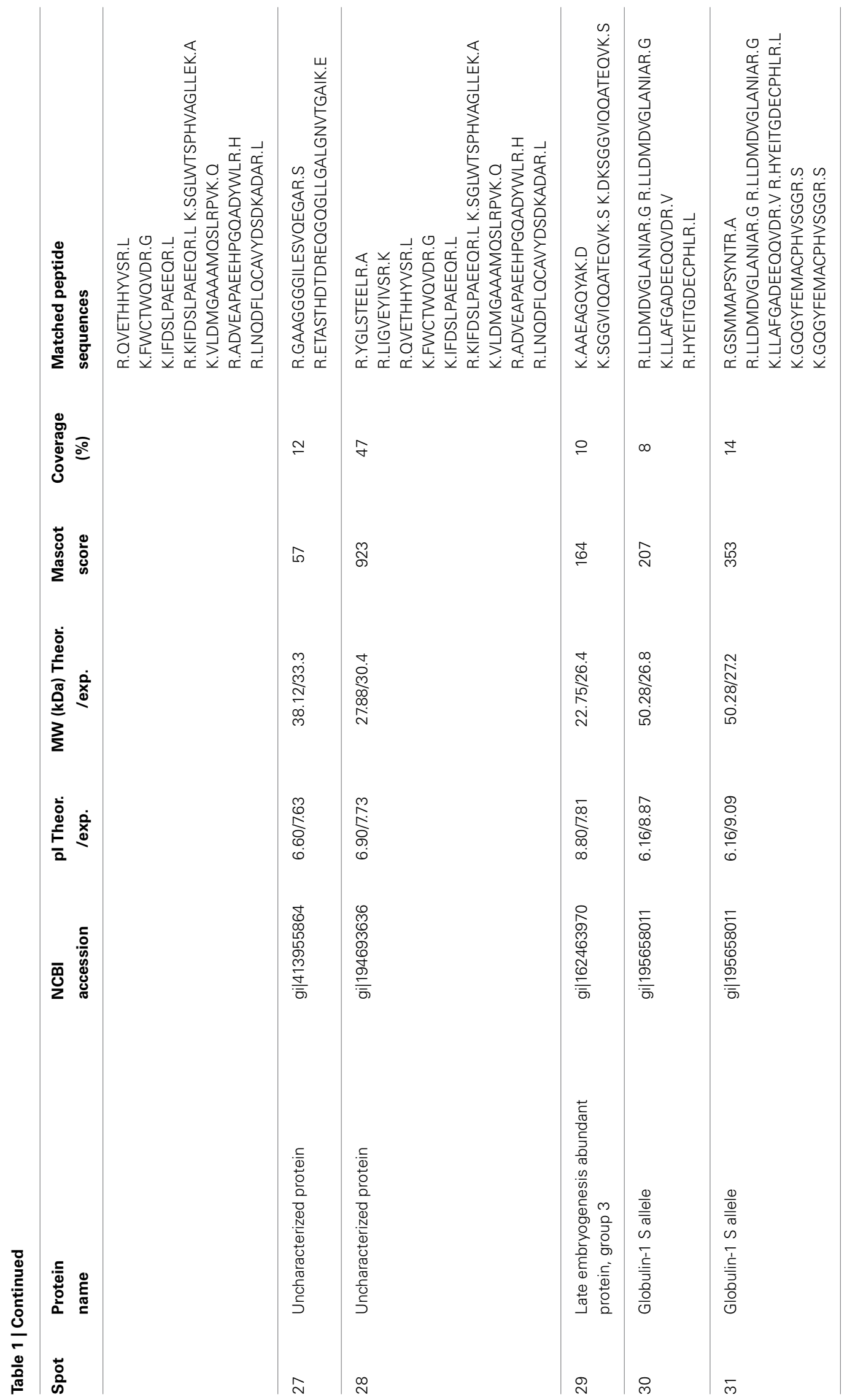


Table 2 | The differentially accumulated proteins identified in maize $v p 5$ and $V p 5$ embryos associated to putative functions.

\begin{tabular}{lllll}
\hline Spot Protein name & UniProtKB accession & $\begin{array}{l}\text { Protein homology } \\
\text { by Blast } \\
\text { (Score/ldentity) }\end{array}$ & $\begin{array}{c}\text { Abundance } \\
\text { change } \\
\text { folds }\end{array}$ & $\begin{array}{l}\text { Subcellular } \\
\text { location }\end{array}$ \\
& (Scoldar function
\end{tabular}

\section{PROTEINS IN INCREASED ABUNDANCE IN vp5 COMPARED TO Vp5}

\section{LEA proteins}

$1 \quad$ Late embryogenesis abundant protein EMB564

$27 \quad$ Uncharacterized protein

HSPs

$2 \quad 17.8 \mathrm{kDa}$ class II heat shock protein

$3 \quad 16.9 \mathrm{kDa}$ class I heat shock protein 1

$4 \quad 17.4 \mathrm{kDa}$ class I heat shock protein 3

$5 \quad$ Heat shock protein 17.9

$6 \quad$ Heat shock protein 17.2

$7 \quad 17.0 \mathrm{kDa}$ class II heat shock protein

$8 \quad 22.0 \mathrm{kDa}$ class IV heat shock protein

$9 \quad 22.0 \mathrm{kDa}$ class IV heat shock protein

$24 \quad 17.4 \mathrm{kDa}$ class I heat shock protein 3

B6TDB5_MAIZE Q43701_MAIZE

Q08275_MAIZE

B6TG53_MAIZE

B6TXB5_MAIZE

B4F976_MAIZE

\section{Oxidoreductase}

10 1-Cys peroxiredoxin PER1

A2SZW8_MAIZE

B4FNZ9_MAIZE

dehydrogenase/reductase

SDR family protein

12 UDP-glucose

6-dehydrogenase

Others

25 Uncharacterized protein

$26 \quad$ Uncharacterized protein

B7ZYX8_MAIZE

B4FFK9_MAIZE

B4FFK9_MAIZE
P46517_MAIZE

K7VM99_MAIZE

Group 3 LEA protein $(1170 / 68.0 \%)$

$\begin{array}{lll}\text { 13.1 } & \text { Nucleus }(\mathrm{Wu} & \text { Stress response } \\ \text { 9. } & \text { Cell., 2013a) } & \\ \text { 9.3all } & \text { Stress response }\end{array}$

$2.4 \quad$ Cytoplasm $^{\mathrm{a}} \quad$ Stress response; protein folding

Stress response; protein processing in ER

$2.4 \quad$ Nucleus $^{\mathrm{b}}$

Stress response; protein folding; protein oligomerization

$2.5 \quad$ Nucleus $^{\text {b }} \quad$ Stress response

$2.5 \quad$ Nucleus $^{\mathrm{b}}$

Stress response: protein processing in ER

$2.1 \quad$ Cytoplasm $^{\mathrm{a}} \quad$ Stress response; protein processing in ER

$2.4 \quad$ Plastid $^{\mathrm{b}}$

$1.5 \quad$ Plastid

$2.8 \quad$ Nucleus $^{b}$

Stress response; protein processing in ER

Stress response; protein processing in ER

Stress response; protein processing in ER

$73 \quad$ Nucleus $^{a}$

Phenylalanine metabolism; biosynthesis of other secondary metabolites

3.6 Plastid ${ }^{\mathrm{b}} \quad$ Oxidation-reduction process

$2.2 \quad$ Plastid

Cell wall pectin metabolic process

Lipoprotein-like

3.1 Plastid

Unknown (1104/ 81.0\%) $(1104 / 81.0 \%)$

\section{PROTEINS IN REDUCED ABUNDANCE IN vp5 COMPARED TO vp5}

\section{LEA proteins}

$\begin{array}{lll}13 & \begin{array}{l}\text { Late embryogenesis } \\ \text { abundant protein D-34 }\end{array} & \text { B6UH67_MAIZE } \\ 14 & \begin{array}{l}\text { Late embryogenesis } \\ \text { abundant protein D-34 }\end{array} & \text { B6UH67_MAIZE }\end{array}$

$\begin{array}{lll}2.2 & \text { Nucleus }^{b} & \text { Stress response } \\ 3.9 & \text { Nucleus }^{b} & \text { Stress response }\end{array}$


Table 2 | Continued

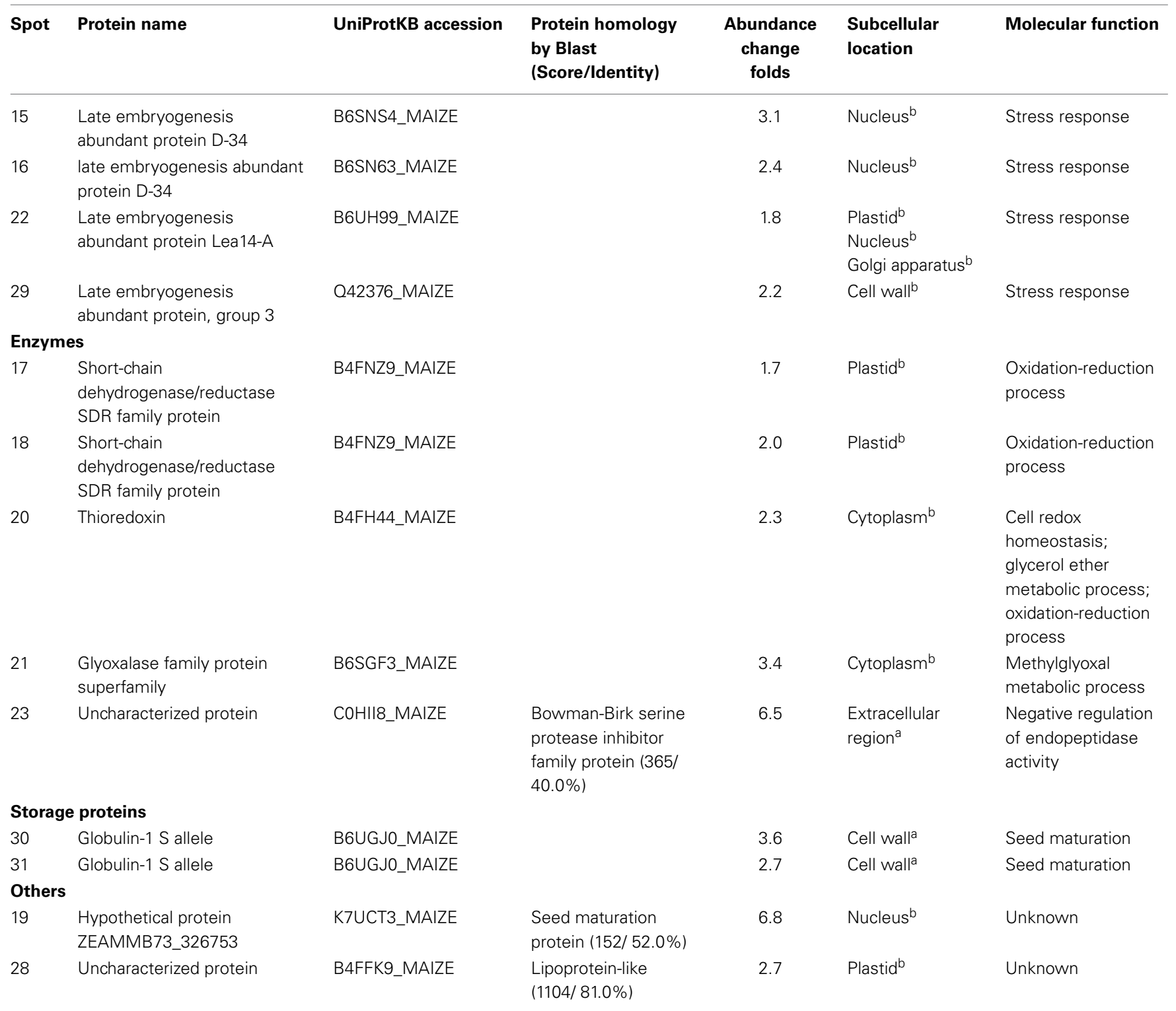

a Subcellular location of proteins was annotated in UniProtKB/Swiss-Prot (http://www.expasy.org/).

${ }^{b}$ Subcellular location of proteins was predicted using the online Plant-mPLoc server (http://www.csbio.sjtu.edu.cn/bioinf/plant-multi/).

IL). The mutant $v p 5$ was propagated in primarily W64 genetic backgrounds. The $v p 5$ mutant was maintained as a heterozygote. Heterozygous seeds ( $V p 5 / v p 5$ ) were planted under natural conditions at the farm of Henan Agricultural University (Zhengzhou, China). The homozygous $v p 5$ kernels were identified on segregating ears by their lack of carotenoid pigments (Robichaud et al., 1980). The mutant $v p 5$ kernels appear white, while Vp5 kernels are yellow. Mature $v p 5$ and $V p 5$ seeds from the same ear were sampled (Presentation 1 in Supplementary Material) used in this study. Dry maize seeds were soaked in water for $2 \mathrm{~h}$ to soften starchy endosperm. For each biological replicate, the embryos and the endosperm of 20 maize seeds were manually separated and used for protein extraction, respectively.

\section{PROTEIN ISOLATION}

Embryos or endosperms were powdered in liquid $\mathrm{N}_{2}$ and further ground in a buffer containing $0.25 \mathrm{M}$ Tris- $\mathrm{HCl}$ ( $\mathrm{pH} 7.5$ ), $1 \%$ SDS, $14 \mathrm{mM}$ DTT and a cocktail of protease inhibitors. This slurry was heated to $65^{\circ} \mathrm{C}$ for $5 \mathrm{~min}$, vortexed, and heated at $95^{\circ} \mathrm{C}$ for $2 \mathrm{~min}$, vortexed again, and then centrifuged at $12,000 \mathrm{~g}$ for $10 \mathrm{~min}$ to remove cellular debris. The supernatant was recovered and subjected to phenol extraction as described (Wu et al., 2014). The protein pellet was dissolved in 2-DE rehydration buffer containing $7 \mathrm{M}$ urea, $2 \mathrm{M}$ thiourea, $2 \%$ (w/v) CHAPS, $20 \mathrm{mM}$ DTT, $0.5 \%$ (v/v) IPG buffer ( $\mathrm{pH} 4-7$ or 7-10, GE Healthcare). The protein content was determined by Bradford microassay (Bio-Rad) with BSA standards. 


\section{SDS-PAGE AND IMMUNOBLOT}

SDS-PAGE was performed in a Laemmli gel system (5\% stacking gel and $12.5 \%$ resolving gel). After electrophoresis, proteins in gels were visualized with colloidal CBB R350 or electroblotted onto polyvinylidene difluoride membrane (Hybond-P, GE healthcare) in a transfer buffer $(20 \% \mathrm{v} / \mathrm{v}$ methanol, $50 \mathrm{mM}$ Tris, $40 \mathrm{mM}$ glycine). For immunoblot analysis, protein blots were soaked in TBST buffer $(50 \mathrm{mM}$ Tris- $\mathrm{HCl}, \mathrm{pH} 7.5,0.15 \mathrm{M} \mathrm{NaCl}$, $0.1 \%$ Tween-20) containing 5\% low fat milk powder and gently shaken for $2 \mathrm{~h}$ at room temperature (RT). The blot was then incubated with anti-EMB564 polyclonal antibody (Wu et al., 2013a, 1: 5000 dilution) for $1 \mathrm{~h}$. After washing with TBST, the blot was incubated in peroxidase-conjugated goat anti-rabbit IgG (1: 2000 dilution) at RT for $1 \mathrm{~h}$. The blot was visualized with $0.08 \%$ 3,3'-diaminobenzidine tetrahydrochloride, $0.05 \% \mathrm{H}_{2} \mathrm{O}_{2}, 0.1 \mathrm{M}$ Tris-HCl, pH 7.5.

\section{2-DE, IMAGE AND DATA ANALYSIS}

Isoelectric focusing (IEF) was performed using $11-\mathrm{cm}$ linear $\mathrm{pH}$ 4-7 IPG strips with the Ettan III system (GE Healthcare, USA). About $600 \mu \mathrm{g}$ proteins were loaded into the strip by passive rehydration overnight at RT. The IEF voltage was set at $250 \mathrm{~V}$ for $1 \mathrm{~h}$, $1000 \mathrm{~V}$ for $4 \mathrm{~h}$, finally increasing to $8000 \mathrm{~V}$ for $4 \mathrm{~h}$, and holding for $10 \mathrm{~h}\left(20^{\circ} \mathrm{C}\right)$. Focused strips were equilibrated in Buffer I $(0.1 \mathrm{M}$ Tris- $\mathrm{HCl}, \mathrm{pH} 8.8,2 \%$ SDS, $6 \mathrm{M}$ urea, 30\% glycerol, $0.1 \mathrm{M}$ DTT) and then in Buffer II (same as Buffer I, but with $0.25 \mathrm{M}$ iodoacetamide instead of DTT) for 15 min each. SDS-PAGE was run on a $13.5 \%$ gel with $0.1 \%$ SDS in the gel and the running buffer. The gels were stained with $0.1 \%$ CBB G-250 overnight and destained in $7 \%$ acetic acid until a clear background.

Protein gels were placed on a white plastic plate with transmission fluorescent lighting, and photographed using a DSLR camera
(Nikon D7000) at an automatic mode. The digital images of the gels were analyzed by using PDQUEST 8.0 software (Bio-Rad). Protein spots were detected on scanned gels using the default spot detection setting. Gels of three biological replicates per genotype were analyzed. The spot intensities were normalized according to total intensity of valid spots to minimize possible errors due to differences in the amount of protein and staining intensity. Analysis of variance (ANOVA) was used to deal with protein spots quantification to identify individual protein spots with significantly different expression levels. Only those proteins with at least 1.5-fold quantitative variations in abundance were selected for mass spectrometry (MS) analysis.

\section{MS/MS}

Protein spots of interest were manually excised from the gels and digested using trypsin. Proteins were reduced $(10 \mathrm{mM}$ DTT), alkylated (50 $\mathrm{mM}$ iodoacetic acid) and then digested with $10 \mathrm{mg} / \mathrm{ml}$ trypsin for $16 \mathrm{~h}$ at $37^{\circ} \mathrm{C}$ in $50 \mathrm{mM}$ ammonium bicarbonate. The supernatants were vacuum-dried and dissolved in $10 \mu \mathrm{l} 0.1 \%$ trifluoroacetic acid and $0.5 \mu \mathrm{l}$ added onto a matrix consisting of $0.5 \mu \mathrm{l}$ of $5 \mathrm{mg} / \mathrm{ml} \mathrm{2,5-dihydroxybenzoic}$ acid in water: acetonitrile $(2: 1)$. The digested fragments were analyzed using a MALDI-TOF/TOF analyzer (ultraflex III, Bruker, Germany). MALDI-TOF/TOF spectra were acquired in the positive ion mode and automatically submitted to Mascot 2.2 (http://www.matrixscience.com, Matrix Science) for peptide mass finger printings against the NCBInr 20131226 database (35149712 sequences; 12374887350 residues, http://www.ncbi. nlm.nih.gov/). The taxonomy was Viridiplantae (green plants, 1669695 sequences). The search parameters were as follows: type of search: MALDI-TOF ion search; enzyme: trypsin; fixed modifications: carbamidomethyl $(\mathrm{C})$; variable modifications: acetyl

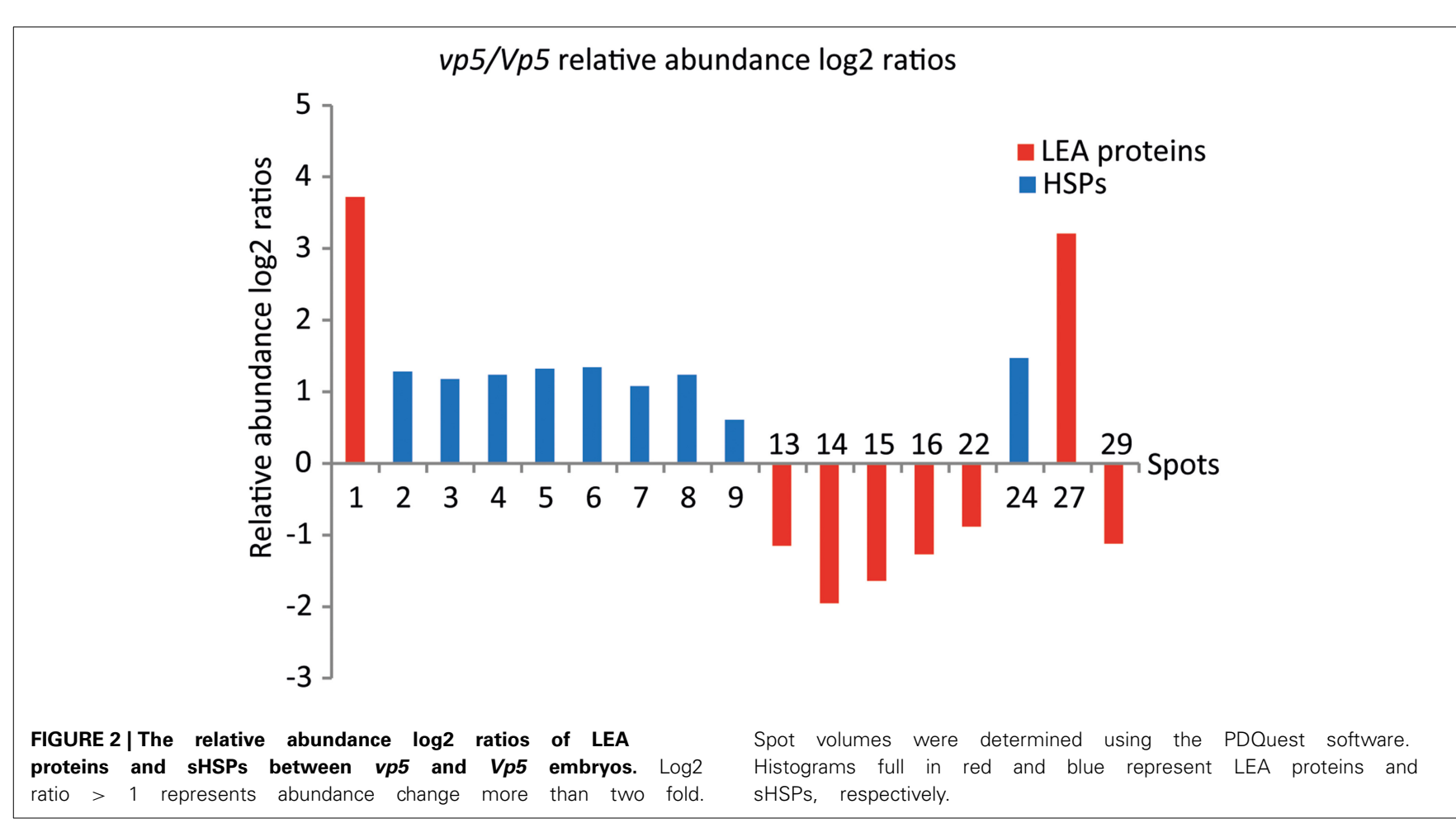


(protein N-terminal) and oxidation (M); mass values: monoisotopic; protein mass: unrestricted; peptide mass tolerance: \pm 50 ppm; fragment mass tolerance: $\pm 0.2 \mathrm{Da}$; max missed cleavages: 1; instrument type: MALDI-TOF. Only significant scores defined by Mascot probability analysis greater than "identity" were considered for assigning protein identity. All of the positive protein identification scores were significant $(P<0.05$, score $>49)$.

\section{BIOINFORMATICS}

To identify the sequences of all putative uncharacterized proteins, BLAST searches (http://www.expasy.org/tools/blast/)

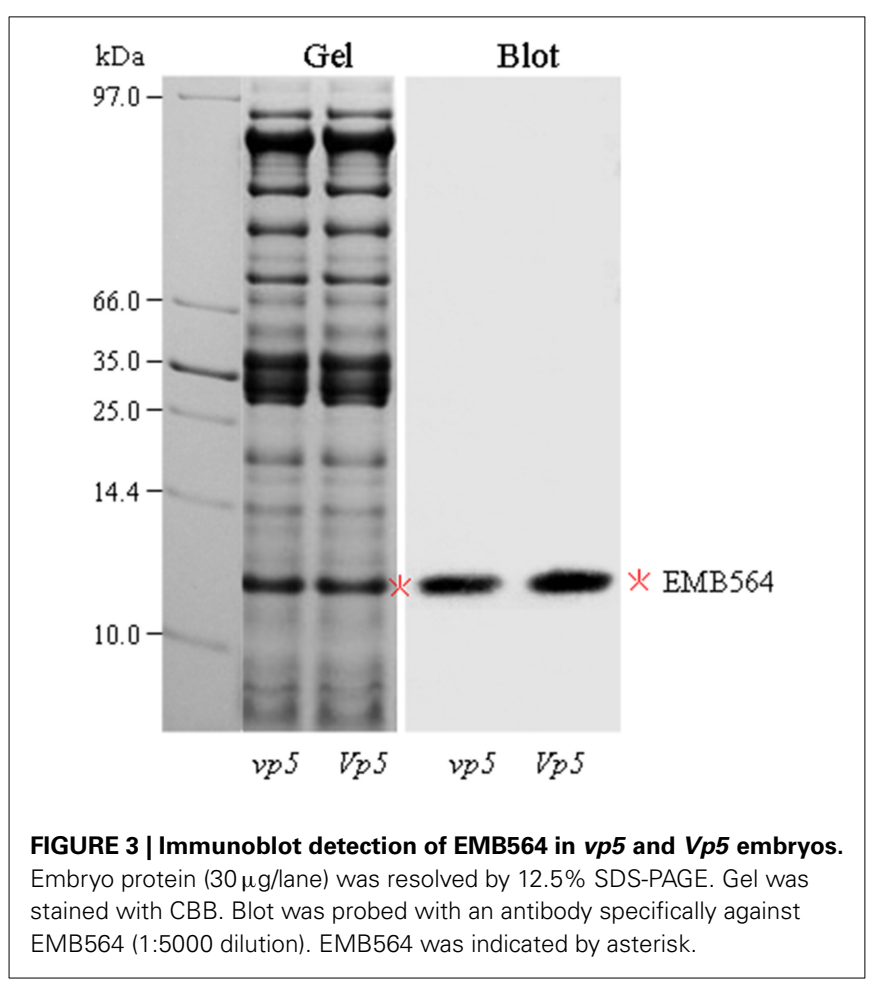

with these protein sequences were performed on the UniProt Knowledgebase (UniProtKB, http://www.uniprot.org/uniprot) to find their homologs. Functional categorization of the identified proteins was based on annotations in UniProtKB and previous studies on their homologs. Subcellular locations of the identified proteins were determined according to the annotation in UniProtKB or predicted at Plant-mPLoc server (http://www.csbio.sjtu.edu.cn/bioinf/plant-multi/). Theoretical $\mathrm{Mr}$ and isoelectric point of proteins were predicted at http://web.expasy.org/compute_pi/. ABA responsive element (ABRE) and dehydration responsive element (DRE) were analyzed using Plantcare (http://bioinformatics.psb.ugent.be/ webtools/plantcare/html/) and PLACE (http://www.dna.affrc.go. jp/PLACE/signalscan.html).

\section{RESULTS}

Maize seed consists of an embryo (a miniature plant), an endosperm (a nutrition provider for seed germination) and a seed coat (protecting structure). To reveal maize seeds proteome alterations due to ABA-deficient mutation and to identify ABA-dependent proteins during seed maturation, embryos and endosperms of the mutant $v p 5$ and wild-type $V p 5$ were used for comparative proteomic analysis. In order to improve protein resolution, two kinds of IPG strips with a $\mathrm{pH}$ range of 4-7 and 7-10 were used in 2-DE.

\section{PROTEOMIC DIFFERENCE BETWEEN vp5 AND Vp5 EMBRYOS}

The embryo protein profiles between $v p 5$ and $V p 5$ were compared by 2-DE. Approximately $780 \pm 10$ and $130 \pm 5 \mathrm{CBB}$-stained protein spots were reproducibly detected using $\mathrm{pH} 4-7$ and 710 IPG gels, respectively (Figure 1). PDQUEST analysis indicated that $96 \%$ of total protein spots were matched, unchanged in abundance between $v p 5$ and $V p 5$ embryos across all the gels (Figure 1, Presentations 2, 3 in Supplementary Material). Spotto-spot comparison revealed that 31 protein spots, i.e., 23 in $\mathrm{pH}$ 4-7 gels (Figure 1A and Presentation 2 in Supplementary Material) and 8 in $\mathrm{pH} 7-10$ gel (Figure 1B and Presentation

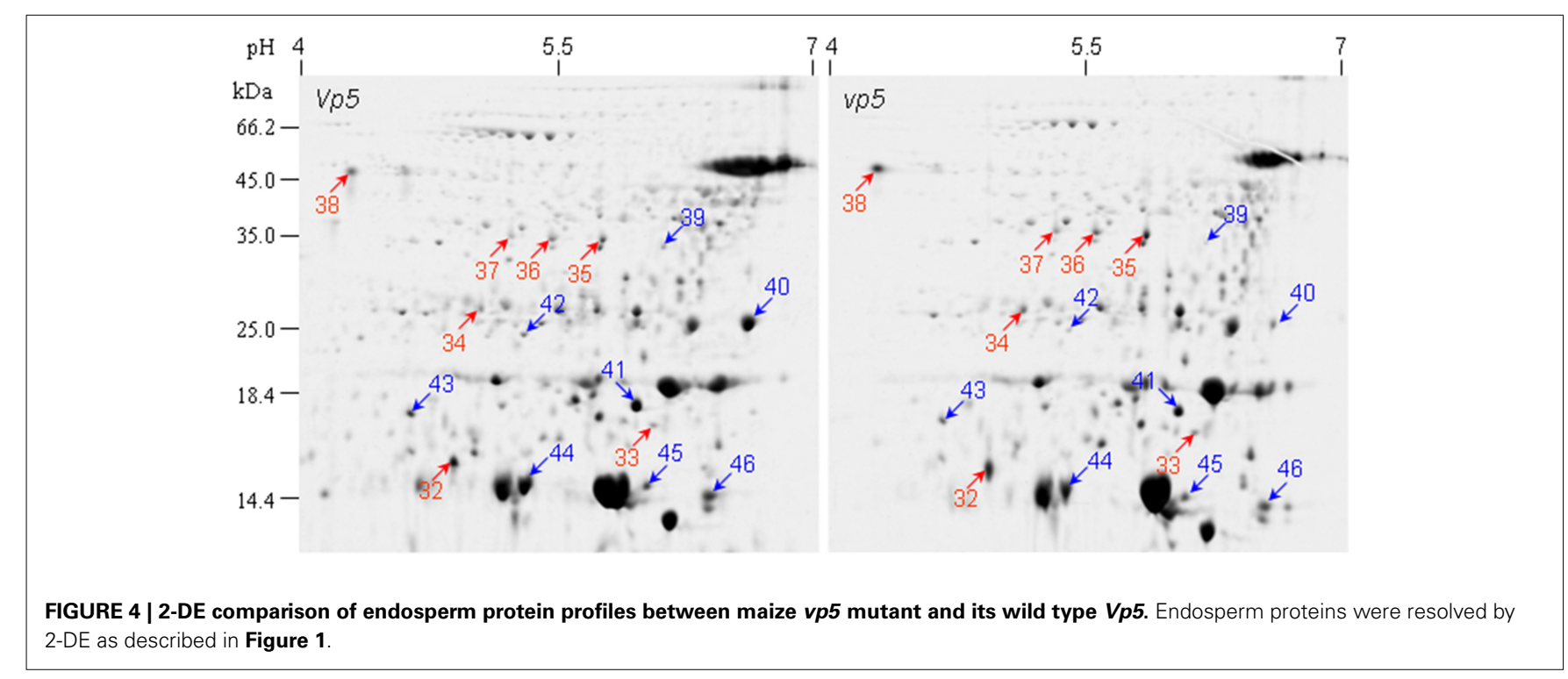




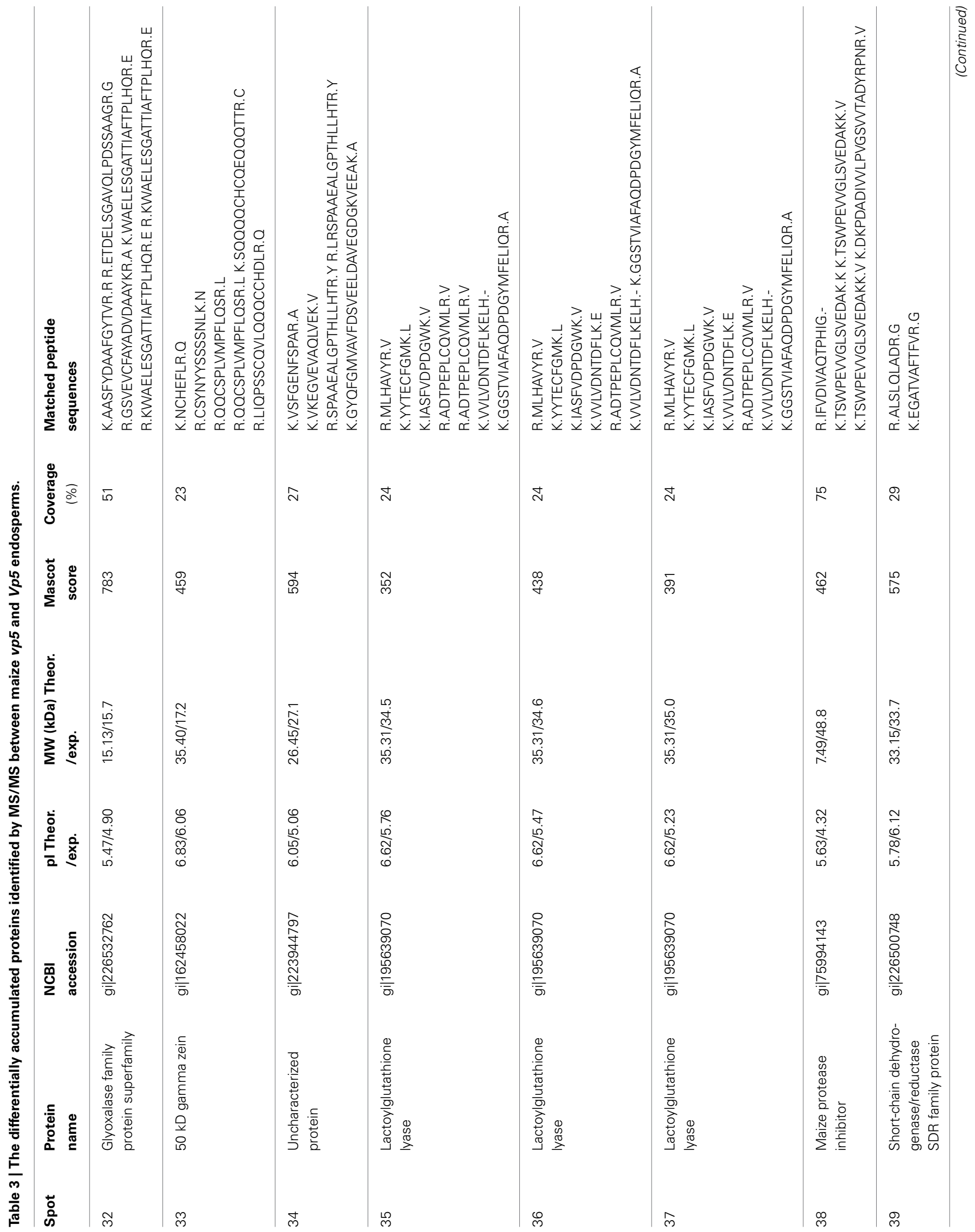




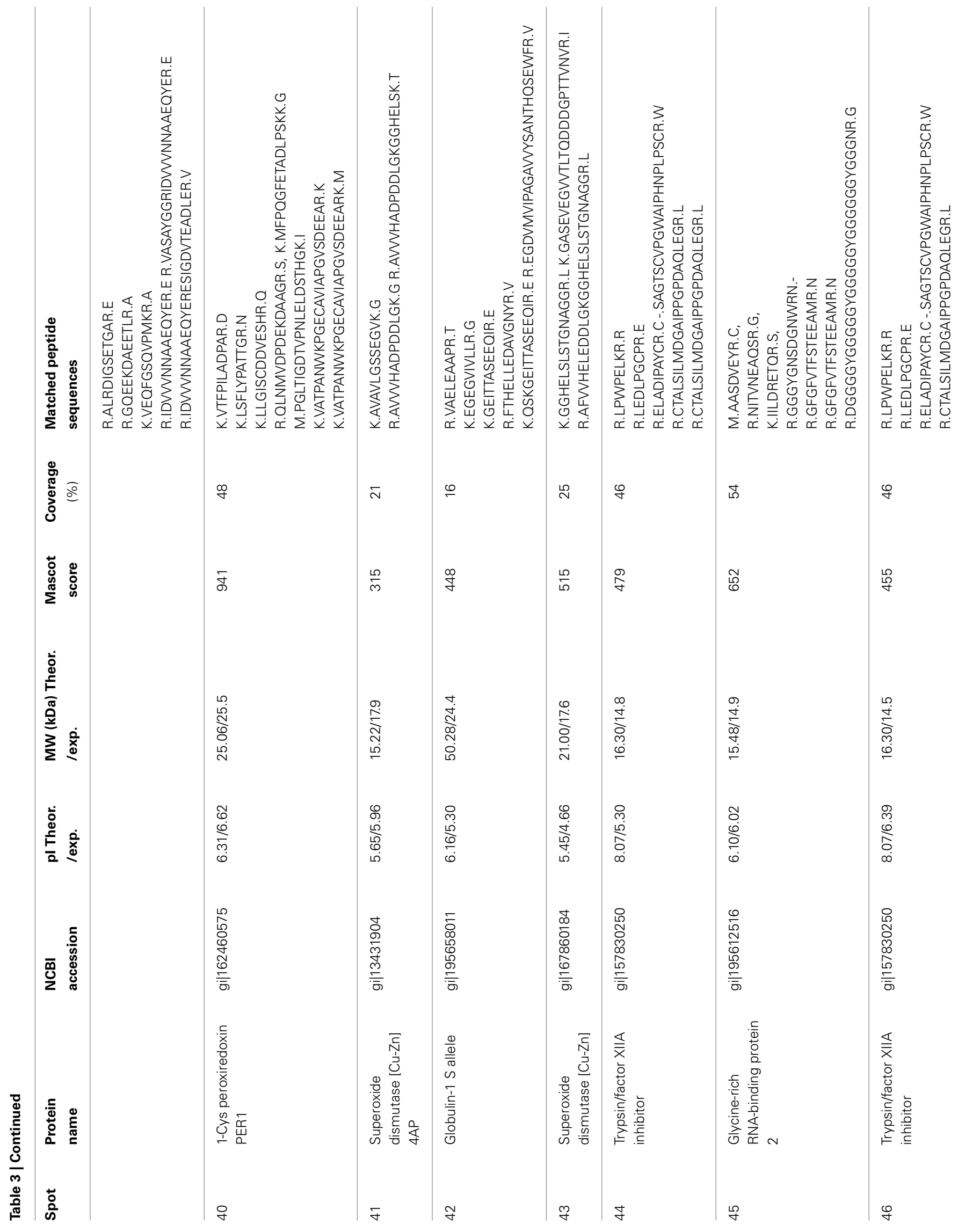


Table 4 | The differentially accumulated proteins identified in maize $v p 5$ and $V p 5$ endosperms associated to putative functions.

\begin{tabular}{|c|c|c|c|c|c|c|}
\hline Spot & $\begin{array}{l}\text { Protein } \\
\text { name }\end{array}$ & $\begin{array}{l}\text { UniProtKB } \\
\text { accession }\end{array}$ & $\begin{array}{l}\text { Protein homology by } \\
\text { Blast (Score/Identity) }\end{array}$ & $\begin{array}{l}\text { Abundance } \\
\text { change folds }\end{array}$ & $\begin{array}{l}\text { Subcellular } \\
\text { location }\end{array}$ & $\begin{array}{l}\text { Molecular } \\
\text { function }\end{array}$ \\
\hline \multicolumn{7}{|c|}{ PROTEINS IN INCREASED ABUNDANCE IN vp5 COMPARED TO Vp5 } \\
\hline 32 & $\begin{array}{l}\text { Glyoxalase family } \\
\text { protein superfamily }\end{array}$ & B6SGF3_MAIZE & & 1.5 & Cytoplasmb & $\begin{array}{l}\text { Methylglyoxal metabolic } \\
\text { process }\end{array}$ \\
\hline 35 & $\begin{array}{l}\text { Lactoylglutathione } \\
\text { lyase }\end{array}$ & B6TPHO_MAIZE & & 1.6 & Cytoplasmb & Metabolic process \\
\hline 36 & $\begin{array}{l}\text { Lactoylglutathione } \\
\text { lyase }\end{array}$ & B6TPHO_MAIZE & & 1.5 & Cytoplasmb & Metabolic process \\
\hline 37 & $\begin{array}{l}\text { Lactoylglutathione } \\
\text { lyase }\end{array}$ & B6TPHO_MAIZE & & 1.7 & Cytoplasmb & Metabolic process \\
\hline 38 & $\begin{array}{l}\text { Maize protease } \\
\text { inhibitor }\end{array}$ & Q2XX01_MAIZE & & 1.9 & $\begin{array}{l}\text { Plastid }^{b} \\
\text { Nucleus }^{b}\end{array}$ & $\begin{array}{l}\text { Proteolysis; response to } \\
\text { wounding }\end{array}$ \\
\hline 34 & $\begin{array}{l}\text { Uncharacterized } \\
\text { protein }\end{array}$ & COHHH9_MAIZE & $\begin{array}{l}\text { Stress responsive } \\
\text { alpha-beta barrel domain } \\
\text { protein }(371 / 42.0 \%)\end{array}$ & 1.5 & Plastid $^{b}$ & Stress response \\
\hline
\end{tabular}

\section{PROTEINS IN REDUCED ABUNDANCE IN vp5 COMPARED TO Vp5}

\section{Enzymes}

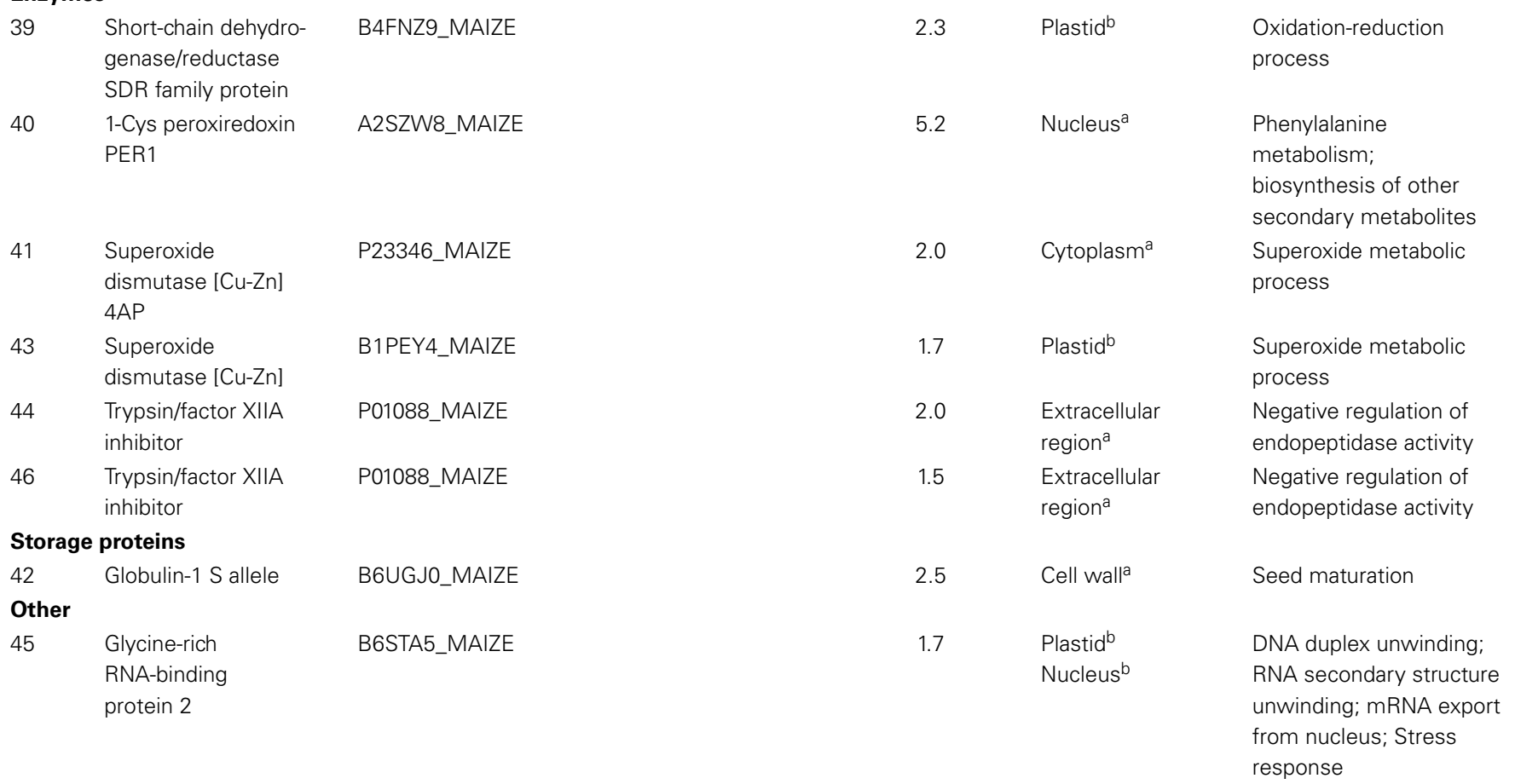

a Subcellular location of proteins was annotated in UniProtKB/Swiss-Prot (http://www.expasy.org/).

${ }^{b}$ Subcellular location of proteins was predicted using the online Plant-mPLoc server (http://www.csbio.sjtu.edu.cn/bioinf/plant-multi/).

3 in Supplementary Material), showed a minimum of a 1.5fold difference in spot volume (Tables 1, 2). Those differentially accumulated embryo protein spots are mainly in the range of $10-35 \mathrm{kDa}$, with a consistent change in three biological replicates, except for three spots in two biological replicates (spot 5, 17, and 22) (Presentation 2 in Supplementary Material). Sixteen embryo protein spots (spots 1-12 and 24-27) accumulated in higher abundance in $v p 5$ compared to $V p 5$ and 15 embryo protein spots (spots 13-23 and 28-31) accumulated in lower abundance in $v p 5$. In particular, the abundance of spots 1,10 , and 27 were $13.71,7.31$, and 9.28 folds higher in $v p 5$ embryos than in $V p 5$ embryos, respectively, whereas the abundance of spots 19 and 23 was 6.76 and 6.52 folds higher in $V p 5$ than in vp5 embryos, respectively. 
Table 5 | Cis-acting elements of LEA and sHSPs proteins analyzed by Plantcare.

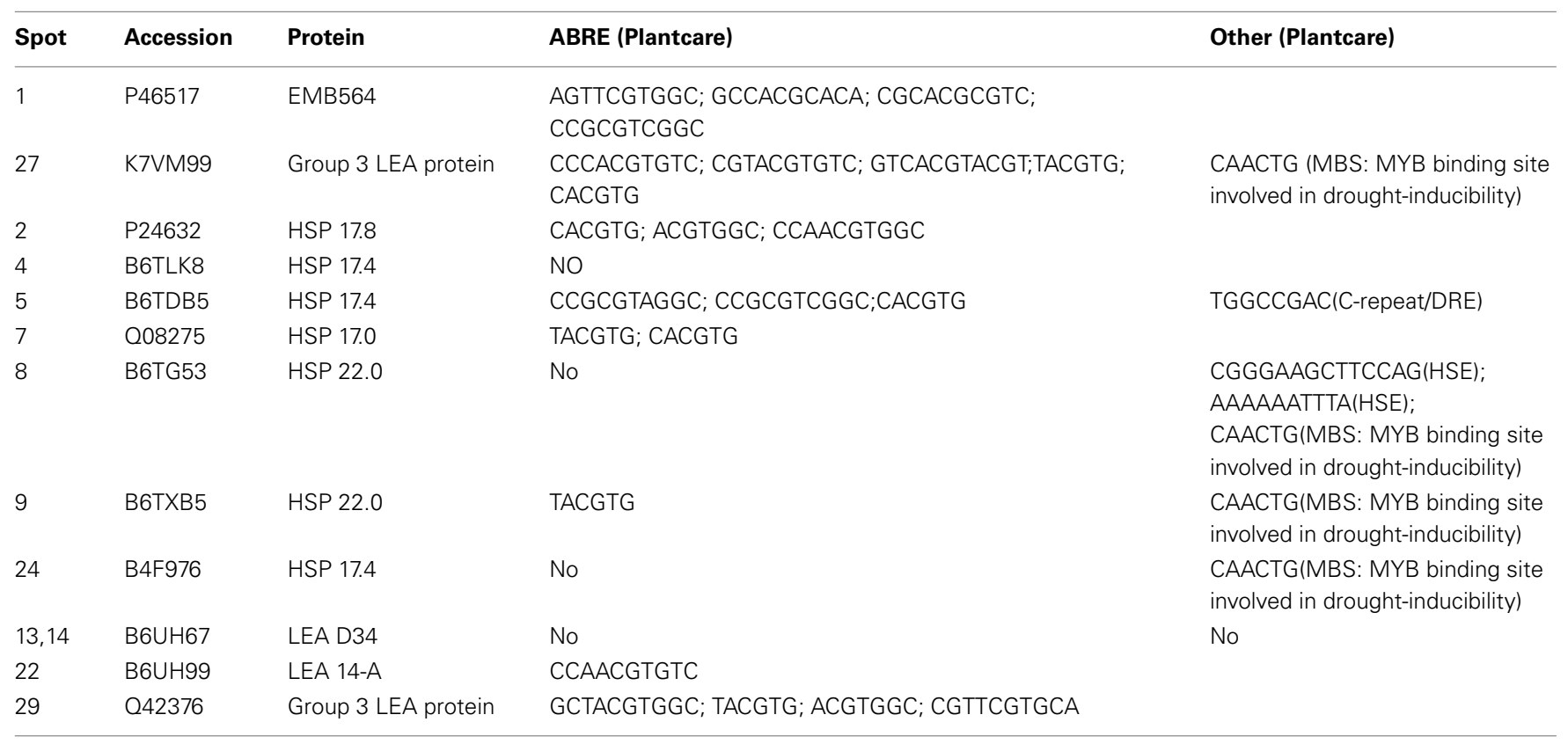

Table 6 | Cis-acting elements of LEA and sHSPs proteins analyzed by Place.

\begin{tabular}{lllll}
\hline Spot & Accession & Protein & ABRE (Place) & DRE (Place) \\
\hline 1 & P46517 & EMB564 & CACGCGT; CACGCGC & GCCGAC(DRECRTCOREAT) \\
27 & K7VM99 & Group 3 LEA protein & ACGTG;TACGTGTC;CACGCGT & ACCGAGA(DRE1COREZMRAB17); \\
& & & & ACCGAC(DRE2COREZMRAB17); \\
& & & ACCGAC(DRECRTCOREAT) \\
2 & P24632 & HSP 17.8 & ACGTG & ACCGAGA(DRE1COREZMRAB17) \\
4 & B6TLK8 & HSP 17.4 & CACGCGGT & GCGAC(DRECRTCOREAT) \\
5 & B6TDB5 & HSP 17.4 & ACGTG & GCCGAC(DRECRTCOREAT) \\
7 & Q08275 & HSP 17.0 & ACGTG;CACGTGT & ACCGAGA(DRE1COREZMRAB17); \\
& & & ACCGAC(DRE2COREZMRAB17); \\
8 & B6TG53 & HSP 22.0 & ACCGAC(DRECRTCOREAT) \\
9 & B6TXB5 & HSP 22.0 & GCGTGAC(DRECRTCOREAT) \\
& & & ACGTG;TACGTGTC & ACCGAGA((DRE1COREZMRAB17); \\
24 & B4F976 & HSP 17.4 & ACCGAC(DRE2COREZMRAB17); \\
13,14 & B6UH67 & LEA D34 & ACCGAC(DRECRTCOREAT) \\
22 & B6UH99 & LEA 14-A & NO & NO \\
29 & Q42376 & Group 3 LEA protein & TACGTGGC; ACGTG; ACGTGGCG; ACGTGGCC; AACGTGG & ACCGAC(DRE2COREZMRAB17); \\
& & & NO & ACCGAC(DRECRTCOREAT) \\
\end{tabular}

The 31 embryo proteins were successfully identified by MS/MS analysis, representing 26 distinct proteins in NCBI or SWISSPROT protein databases (Tables 1, 2). In several cases, proteins were identified as uncharacterized proteins. We searched their homologous proteins in other plant species by BLAST, such as spot 19 homologous to seed maturation protein of Glycine latifolia (identity of $40 \%$ ) and spots 25,26 , and 28 homologous to lipoprotein-like of Oryza sativa (rice, identity of $81 \%$ ), or were based on family and domain databases, such as spot 23 belonging to Bowman-Birk serine protease inhibitor family, and spot 27 belonging to group 3 LEA protein. These differentially accumulated protein spots were assigned to various LEA family proteins (spots 1, 13-16, 22, 27, and 29), HSP20 family proteins (spots 2-9 and 24), 1-Cys peroxiredoxin PER1 (spot 10), short-chain dehydrogenase/reductase SDR family protein (spot 11, 17, and 18), UDP-glucose 6-dehydrogenase (spot 12), seed maturation protein (spot 19), thioredoxin (spot 20), glyoxalase family protein (spot 21), Bowman-Birk serine protease inhibitor family protein (spot 23), lipoprotein-like (spot 25, 26, and 28), and globulin-1 S allele (spots 30 and 31 ). Nine sHSPs accumulated in higher abundance 
in $v p 5$ embryos, while six out of eight LEA proteins (except for spots 1 and 27) accumulated in higher abundance in $V p 5$ embryos (Figure 2).

In the present study, two identified proteins belong to group 3 LEA protein (spot 27, K7VM99, spot 29 Q42376), but they exhibit opposite accumulation between $v p 5$ and $V p 5$ embryos. In $v p 5$ embryos, Q42376, like other five identified LEA proteins, decreased in abundance, while K7VM99, like nine identified sHSPs, increased in abundance. This discrepancy may be explained by protein and gene sequence differences. K7VM99 and Q42376 share only a 35\% identity in protein sequence alignment by BLAST.

In addition, we found EMB564 existed in two isoforms: a weak spot 1 and a most predominant spot (indicated in Figure 1A). These two isoforms displayed a contrast accumulation in $v p 5$ compared to Vp5: the weak isoform (spot 1) increased greatly whereas the other decreased a little. However, the total abundance of EMB564 was comparable between $v p 5$ and $V p 5$. This result contrasted to previously characterized, greatly lowered expression of emb564 mRNA in vp5 embryos (Williams and Tsang, 1991). In order to further confirm the accumulation level of EMB564 in the two genotypes, we examined the abundance of EMB564 using immunoblot analysis (Figure 3). The specificity of the antibody has been recently characterized, and it specifically reacts with EMB564 (Wu et al., 2013a). Obviously, EMB564 existed in comparable levels between $v p 5$ and $V p 5$ embryos, with a slightly reduced level in $v p 5$.

\section{PROTEOMIC DIFFERENCE BETWEEN vp5 AND Vp5 ENDOSPERMS}

In preliminary 2-DE experiments, none obviously differentially accumulated endosperms protein spots were observed to exist when pH 7-10 IPG gels were used (data not shown). Therefore, endosperm proteome analysis was performed only using $\mathrm{pH}$ 4-7 IPG gels.

The endosperm protein profiles between $v p 5$ and $V p 5$ were compared by 2-DE. Approximately $380 \pm 10 \mathrm{CBB}$-stained protein spots were detected in endosperms, which was much less compared to embryos and most of proteins existed in low abundance (Figure 4). PDQUEST analysis indicated that 15 protein spots, especially spot 40 , showed an obvious difference between $v p 5$ and $V p 5$ endosperms, with a consistent change in three biological replicates (Figure 4, Presentation 4 in Supplementary Material). Seven spots (32-38) existed in higher abundance and eight spots (39-46) in lower abundance in $v p 5$. These differentially accumulated protein spots were successfully identified by MS/MS (Tables 3, 4), representing 11 unique protein species.

\section{DISCUSSION \\ GLOBAL PROTEOME ALTERATIONS IN EMBRYO AND ENDOSPERM OF MAIZE vp5 AND Vp5}

Maize viviparous mutants, germinating directly on the ear (McCarty et al., 1991), are widely used for studying maize seed maturation, dormancy, and germination. Various viviparous mutants have been identified, such as $v p 1 、 v p 2 、 v p 5 、 v p 7 、 v p 8$ 、 and $v p 9$. Among them, $v p 5$ mutant is deficient in ABA biosynthesis with the first step catalyzed by phytoene desaturase being blocked, resulting in the precursor phytoene accumulation and carotenoid deficiency (Robichaud et al., 1980). However, the background difference at proteome level between $v p 5$ and $V p 5$ seeds is still unclear.

In the present study, comparative proteomics was used to determine the variation of protein expression at the proteome level between maize mutant $v p 5$ and its wild type Vp5. There are great differences in the structure, composition and function between embryo and endosperm of maize seeds. Compared to endosperm, embryo is more active in nucleic acid, protein, and lipid metabolism. In total, 46 seed protein spots were found to be exhibited a differential change in abundance between these two genotypes, 31 spots in embryo and 15 spots in endosperm. Obviously, proteome alterations caused by ABA-deficient mutation are more significant in embryos than in endosperms in $v p 5$ seeds. This may be explained by two possible causes: Firstly, ABA deficiency mainly takes place in $v p 5$ embryos. Due to deficient in ABA biosynthesis, maize vp5 embryos contains a low ABA content (about $10 \%$ of $V p 5$ ) throughout seed maturation, whereas $42 \%$ ABA in $v p 5$ endosperms (Neill et al., 1986). ABA in endosperm can be from maternal organs (Ober and Setter, 1992). Secondly, maize endosperms act mainly as starch storage tissue and contain fewer proteins in low amounts in mature seeds. Although ABA-deficient mutation affects the phenotype of $v p 5$ endosperm (carotenoid deficiency), proteins or enzymes involved in the related pathways were not detected, probably due to their low abundance and low sensitivity of CBB staining.

In the present study, four proteins, i.e., 1-Cys peroxiredoxin PER1 (spot 10 in embryo, spot 40 in endosperm), globulin-1 s allele (spot 30 and 31 in embryo, spot 42 in endosperm), glyoxalase family protein (spots 21 in embryo and 32 in endosperm) and short-chain dehydrogenase/reductase SDR family protein (spot 11, 17, and 18 in embryo, spot 39 in endosperm) were the same as identified embryo proteins. Among them, globulin$1 \mathrm{~s}$ allele (spot 30, 31, and 42) and short-chain dehydrogenase/reductase SDR family protein (spot 17, 18, and 39) decreased both in $v p 5$ embryo and endosperm compared to $V p 5$.

It is worth to note that EMB564, the most abundant LEA protein in maize embryos, was found to exist in comparable levels between $v p 5$ and $V p 5$ embryos. EMB564 consists of two isoforms with obvious differences in apparent and theoretical values of sizes and isoelectric points, indicating a post-translational modification of this protein (e.g., phosphorylation, Amara et al., 2012). Williams and Tsang (1991) first cloned and characterized an embryo-specific recombinant, termed emb564 [recently renamed as embryo specific protein 1 (esp1) in NCBI database]. The emb564 mRNA is expressed at low level in ABA-deficient (e.g., vp5) but not in ABA-insensitive (e.g., $v p 1$ ) embryos during embryogenesis, and exogenous ABA has little effect on the accumulation of emb564 mRNA in more mature embryos (Williams and Tsang, 1991). Therefore, there is a discrepancy between EMB564 protein and mRNA levels.

The transcript/protein discordance has been well documented in mammals, yeasts and plants (mainly Arabidopsis and maize). It is largely of biological origin ("true discordance") and of post-transcriptional regulation (Vélez-Bermúdez and Schmidt, 2014). For example, in Arabidopsis roots, a lack of correlation between down-regulated transcripts and the amount of their 
corresponding proteins was observed in response to phosphate deficiency, whereas for induced genes changes in the levels of mRNAs and proteins were reasonably well correlated (Lan et al., 2012). In the ABA-deficient $v p 5$ embryos, EMB564 can accumulate to a similar level as its wild type. Thus, this transcript/protein discordance is possibly caused by post-transcriptional regulation (via unknown factors) in an ABA-independent way.

Recently, we found that EMB564 is associated with maize seed vigor (Wu et al., 2011) and is highly thermal stable (Wang et al., 2012). By immunoelctron microscopy, we showed that EMB564 locates preferentially in the nucleus of maize embryonic cells (Wu et al., 2013a). Likewise, Amara et al. (2012) demonstrated that EMB564-green fluorescent protein fusions are expressed in the cytosol and nucleus in the agroinfiltrated leaves of Nicotiana bentamiana. Based on bioinformatics analysis, we proposed that EMB564 may function within the nucleus by binding DNA (Wu et al., 2013b).

In addition, we also noticed that some spots are not consistent in abundance between the biological replicates. This inconsistence results mainly from inherit drawbacks of 2-DE (e.g., poor reproducibility between gels) and from minor changes in manipulation during protein extraction among independent biological experiments. However, only those reproducibly, differentially accumulated proteins between $v p 5$ and $V p 5$ are subjected to MS/MS analysis.

\section{LEA PROTEINS AND SHSPS DISPLAYED DIFFERENTIAL ACCUMULATIONS IN ABA-DEFICIENT EMBRYOS}

The most interesting finding in this study is that most LEA proteins and sHSPs displayed differential accumulations in ABAdeficient $v p 5$ embryos: six out of eight identified LEA proteins decreased while nine identified sHSPs increased in abundance, compared to Vp5.

LEA proteins are characterized by high hydrophilicity and accumulate to high levels during the last stage of seed maturation (Dure et al., 1989; Espelund et al., 1992). Although the roles of LEA proteins remain speculative, there is evidence supporting their participation in acclimation and/or in the adaptive response to dehydration, low temperature, salinity, or exogenous ABA treatment stress (Battaglia et al., 2008). sHSPs are produced in seeds during maturation and under various stress conditions. The synthesis of sHSPs during seed maturation indicates their probable role in cell component protection mechanisms. Mutants sensitive to desiccation contain smaller amounts of sHSPs during maturation (Wehmeyer and Vierling, 2000).

We tried to explain the possible causes of the observed differential accumulation of six identified LEA proteins and nine identified sHSPs between $v p 5$ and Vp5 seeds. Firstly, the threshold content of ABA inducing the accumulation of LEA proteins and sHSPs may differ: some LEA proteins may require higher ABA content than sHSPs during seed maturation. ABA-deficiency in $v p 5$ embryos greatly inhibited the accumulation of most LEA proteins, but promoted the accumulation of sHSPs. In another words, compared to developmentally specific accumulation of LEA proteins, sHSPs seemed to be less strictly ABA-dependent. In the ABA-deficient $v p 5$ embryos, EMB564 accumulates to a similar level as its wild type, implying an ABA-independent accumulation of EMB564 in maize embryos. This deduction will be examined by measuring the ABA content and the time-course of accumulation of LEA proteins and sHSPs during $v p 5$ seed development in future. Previously, differential regulation of ABA-induced 23$25 \mathrm{kDa}$ proteins in embryo and vegetative tissues of maize $v p$ mutants was reported (Pla et al., 1989). In a recent study, we identified several proteins in maize $V p 5$ and $v p 5$ seedlings whose syntheses are ABA-independent, such as ADP-dependent malic enzyme and fructose-bisphosphate aldolase (Hu et al., 2012). Maize seeds undergo dehydration process during maturation. ABA mutant $v p 5$ seeds contain low ABA content and lack obvious dehydration process; therefore, the accumulation of strict ABAdependent protein (e.g., LEA proteins in this study) may reduce, and not strict ABA-dependent proteins (e.g., sHSPs in this study) may increase to enhance seed dehydration/drought tolerance.

We checked whether there was any difference in the promoter region, especially regarding ABRE and DRE, between differentially accumulated proteins identified here (Tables 5, 6). Most LEA genes are sensitive to ABA because of the presence of $A B R E$, i.e., regulatory elements in promoter regions, which contain the ACGT sequence called cassette G. Sensitivity to ABA also depends on the presence of MYC elements that include the sequence CACCTG, and MYB elements that include the TAACTG motive (Kalemba and Pukacka, 2007). Dehydration responsive element, DRE, is 9-bp consensus sequence, TACCGACAT, was first identified in the promoter of Arabidopsis rd29A/lti78 and shown to be essential for drought induction in the absence of ABA (Yamaguchi-Shinozaki and Shinozaki, 1994).

In addition, the accumulation pattern of group 3 LEA protein (spot 27, K7VM99) in $v p 5$ embryo is different with other five identified LEA proteins. The group 3 LEA proteins are characterized by a repeating motif of 11 amino acids (TAQAAKEKAGE) (Dure et al., 1989), which are quite diverse in sequence structure compared with other LEA groups (Battaglia et al., 2008). In maize $v p 5$ seeds, group 3 LEA protein accumulation is dependent upon ABA (Thomann et al., 1992), whereas corresponding mRNA has no response to exogenous ABA (White and Rivin, 2000). In maize leaves, group 3 LEA gene can be induced by ABA (Liu et al., 2013). Cis-acting elements analysis showed that group 3 LEA protein (K7VM99) shares more identical ABRE and/or DRE with sHSPs (e.g., HSP 17.0) than other LEA proteins (Tables 5, 6). This may explain why group 3 LEA protein (K7VM99) differentially accumulates in $v p 5$ embryos, like sHSPs but unlike other LEA proteins.

In conclusion, comparative gel-based proteomics revealed significant proteome difference between $v p 5$ and $V p 5$ seeds. Most notably, LEA proteins and sHSPs displayed a differential accumulation pattern in ABA-deficient $v p 5$ embryos. The data derived from the present study is highly applicable to other crops. The characterization of proteome difference between $v p 5$ and $V p 5$ seeds is necessary for dissection of ABA-mediated maize response in the studies involved $v p 5$ mutants. The data derived from this study provides insight into ABA-dependent proteins and $\mathrm{ABA}-$ mediated response during seed maturation in maize. 


\section{ACKNOWLEDGMENTS}

This research was supported by National Natural Science Foundation of China (grant 31371543 and 31171470), Plan for Scientific Innovation Talent of Henan Province (grant 144200510012) and State Key Laboratory of Crop Biology (2012KF01) at Shandong Agricultural University, China.

\section{SUPPLEMENTARY MATERIAL}

The Supplementary Material for this article can be found online at: http://www.frontiersin.org/journal/10.3389/fpls.2014.00801/ abstract

\section{REFERENCES}

Amara, I., Odena, A., Oliveira, E., Moreno, A., Masmoudi, K., Pagès, M., et al. (2012). Insights into maize LEA proteins: from proteomics to functional approaches. Plant Cell Physiol. 53, 312-329. doi: 10.1093/pcp/ pcr 183

Battaglia, M., Olvera-carrillo, Y., Garciarrubio, A., Campos, F., and Covarrubias, A. A. (2008). The enigmatic LEA proteins and other hydrophilins. Plant Physiol. 148, 6-24. doi: 10.1104/pp.108.120725

Durantini, D., Giulini, A., Malgioglio, A., Pilu, R., Tuberosa, R., Sanguineti, C., et al. (2008). Vivipary as a tool to analyze late embryogenic events in maize. Heredity 101, 465-470. doi: 10.1038/hdy.2008.29

Dure, L., Crouch, M., Harada, J. J., Ho, T. H. D., Mundy, J., Quatrano, R., et al. (1989). Common amino acid sequence domains among the LEA proteins of higher plants. Plant Mol. Biol. 12, 475-486. doi: 10.1007/BF000 36962

Espelund, M., Saeboe-Larssen, S., Hughes, D. W., Galau, G. A., Larsen, F., and Jakobsen, K. S. (1992). Late embryogenesis-abundant genes encoding proteins with different numbers of hydrophilic repeats are regulated differentially by abscisic acid and osmotic stress. Plant J. 2, 241-252.

Hable, W. E., Oishi, K. K., and Schumaker, K. S. (1998). Viviparous-5 encodes phytoene desaturase, an enzyme essential for abscisic acid (ABA) accumulation and seed development in maize. Mol. Gen. Genet. 257, 167-176. doi: 10.1007/s004380050636

Hu, X. L., Lu, M. H., Li, C. H., Liu, T. X., Wang, W., Wu, J., et al. (2011). Differential expression of proteins in maize roots in response to abscisic acid and drought. Acta Physiol. Plant. 33, 2437-2446. doi: 10.1007/s11738-0110784-y

Hu, X. L., Wu, X. L., Li, C. H., Lu, M. H., Liu, T. X., Wang, Y., et al. (2012). Abscisic acid refines the synthesis of chloroplast proteins in maize (Zea mays) in response to drought and light. PLoS ONE 7:e49500. doi: 10.1371/journal.pone.00 49500

Kalemba, E. M., and Pukacka, S. (2007). Possible roles of LEA proteins and sHSPs in seed protection: a short review. Biol. Lett. 44, 3-16.

Lan, P., Li, W., and Schmidt, W. (2012). Complementary proteome and transcriptome profiling in phosphate-deficient Arabidopsis roots reveals multiple levels of gene regulation. Mol. Cell. Proteomics 11, 1156-1166. doi: 10.1074/mcp.M112.020461

Lehesranta, S. J., Davies, H. V., Shepherd, L. V. T., Nunan, N., McNicol, J. W., Auriola, S., et al. (2005). Comparison of tuber proteomes of potato varieties, Landraces, and genetically modified lines. Plant Physiol. 138, 1690-1699. doi: 10.1104/pp.105.060152

Liu, Y., Wang, L., Xing, X., Sun, L. P., Pan, J. W., Kong, X. P., et al. (2013). ZmLEA3, a multifunctional group 3 LEA protein from maize (Zea mays L.), is involved in biotic and abiotic stresses. Plant Cell Physiol. 54, 944-959. doi: $10.1093 / \mathrm{pcp} / \mathrm{pct} 047$

Ma, Y., Szostkiewicz, I., Korte, A., Moes, D., Yang, Y., Christmann, A., et al. (2009). Regulators of PP2C phosphatase activity function as abscisic acid sensors. Science 324, 1064-1068. doi: 10.1126/science.1172408

McCarty, D. R., Hattori, T., Carson, C. B., Vasil, V., Lazar, M., and Vasil, I. K. (1991). The Viviparous-1 developmental gene of maize encodes a novel transcriptional activator. Cell 66, 895-905. doi: 10.1016/0092-8674(91) 90436-3

Moore, K. B., and Oishi, K. K. (1994). 3-Hydroxy-3-methylglutaryl coenzyme A reductase activity in the endosperm of maize vivipary mutants. Plant Physiol. $105,119-125$.
Neill, S. J., Horgan, R., and Parry, A. D. (1986). The carotenoid and abscisic acid content of viviparous kernels and seedlings of Zea mays L. Planta 169, 87-96. doi: 10.1007/BF01369779

Nishimura, N., Sarkeshi, A., Nito, K., Park, S. Y., Wang, A., Carvalho, P. C., et al. (2010). PYR/PYL/RACR family members are major in vivo ABIl protein phosphatase 2c interacting proteins in Arabidopsis. Plant J. 61, 290-299. doi: 10.1111/j.1365-313X.2009.04054.x

Ober, E. S., and Setter, T. L. (1992). Water deficit induces abscisic acid accumulation in endosperm of maize viviparous mutants. Plant Physiol. 98, 353-356. doi: 10.1104/pp.98.1.353

Park, S. Y., Fung, P., Nishimura, N., Jensen, D. R., Fujii, H., Zhao, Y.,et al. (2009). Abscisic acid inhibits type 2c protein phosphatases via the PYR/PYL family of START proteins. Science 324, 1068-1071. doi: 10.1126/science.11 73041

Pla, M., Goday, A., Vilardell, J., Gomez., J., and Pages, M. (1989). Differential regulation of the ABA-induced $23-25 \mathrm{kD}$ proteins in embryos and vegetative tissues of the viviparous mutants of maize. Plant Mol. Biol. 13, 385-394. doi: 10.1007/BF00015550

Quatrano, R. S. (1986). Regulation of gene expression by abscisic acid during angiosperm embryo development. Oxford Surveys Plant Mol. Cell Biol. 3, 467-477.

Robichaud, C. S., Wong, J., and Sussex, I. M. (1980). Control of in vitro growth of viviparous embryo mutants of maize by abscisic acid. Dev. Genet. 1, 325-330. doi: $10.1002 /$ dvg.1020010405

Santiago, J., Dupeux, F., Round, A., Antoni, R., Park, S. Y., Jamin, M., et al. (2009). The abscisic acid receptor PYR1 in complex with abscisic acid. Nature 462, 665-668. doi: 10.1038/nature08591

Tan, B. C., Schwartz, S. H., Zeevaart, J. A., and McCarty, D. R. (1997). Genetic control of abscisic acid biosynthesis in maize. Proc. Natl. Acad. Sci. U.S.A. 94, 12235-12240. doi: 10.1073/pnas.94.22.12235

Thomann, E. B., Sollinger, J., White, C., and Rivin, C. J. (1992). Accumulation of group 3 late embryogenesis abundant proteins in Zea mays embryos: roles of abscisic acid and the Viviparous-1 gene product. Plant Physiol. 99, 607-614. doi: 10.1104/pp.99.2.607

Umezawa, T., Nakashima, K., Miyakawa, T., Kuromori, T., Tanokura, M., Shinozaki, K., et al. (2010). Molecular basis of the core regulatory network in ABA responses: sensing, signaling and transport. Plant Cell Physiol. 51, 1821-1839. doi: $10.1093 / \mathrm{pcp} / \mathrm{pcq} 156$

Vélez-Bermúdez, I. C., and Schmidt, W. (2014). The conundrum of discordant protein and mRNA expression. Are plants special? Front. Plant Sci. 5:619. doi: 10.3389/fpls.2014.00619

Wang, W., Wu, X. L., Xiong, E. H., and Tai, F. J. (2012). Improving gel-based proteome analysis of soluble protein extracts by heat prefractionation. Proteomics 12, 938-943. doi: 10.1002/pmic.201100475

Wehmeyer, N., and Vierling, E. (2000). The expression of small heat shock proteins in seeds responds to discrete development signals and suggest a general protective role in desiccation tolerance. Plant Physiol. 122, 1099-1108. doi: 10.1104/pp.122.4.1099

White, C. N., and Rivin, C. J. (2000). Gibberellins and seed development in maize. ii. gibberellin synthesis inhibition enhances abscisic acid signaling in cultured embryos. Plant Physiol. 122, 1089-1097. doi: 10.1104/pp.122. 4.1089

Williams, B., and Tsang, A. (1991). A maize gene expressed during embryogenesis is abscisic acid-inducible and highly conserved. Plant Mol. Biol. 16, 919-923. doi: 10.1007/BF00015086

Wu, X. L., Gong, F. P., and Wang, W. (2013b). Functional assignment to maize group 1 LEA protein EMB564 within the cell nucleus using computational analysis. Bioinformation 9, 276-279. doi: 10.6026/97320630 009276

Wu, X. L., Liu, H. Y., Wang, W., Chen, S. N., Hu, X. L., and Li, C. H. (2011). Proteomic analysis of seed viability in maize. Acta Physiol. Plant. 33, 181-191. doi: 10.1007/s11738-010-0536-4

Wu, X. L., Scali, M., Faleri, C., and Wang, W. (2013a). Polyclonal antibody preparation and immunolocalization of maize (Zea mays) seed protein. Plant Omics J. 6, 359-363.

Wu, X. L., Xiong, E. H., Wang, W., Scali, M., and Cresti, M. (2014). Universal sample preparation method integrating trichloroacetic acid/acetone precipitation with phenol extraction for crop proteomic analysis. Nat. Protoc. 9, 362-374. doi: 10.1038/nprot.2014.022 
Yamaguchi-Shinozaki, K., and Shinozaki, K. (1994). A novel cis-acting element in an Arabidopsis gene is involved in responsiveness to drought, low-temperature, or high-salt stress. Plant Cell 6, 251-264. doi: 10.1105/tpc.6.2.251

Zeevaart, J. A. D., and Creelman, R. A. (1988). Metabolism and physiology of abscisic acid. Annu. Rev. Plant Physiol. Plant Mol. Biol. 39, 439-473 doi: 10.1146/annurev.pp.39.060188.002255

Conflict of Interest Statement: The authors declare that the research was conducted in the absence of any commercial or financial relationships that could be construed as a potential conflict of interest.

Received: 20 October 2014; paper pending published: 27 November 2014; accepted: 22 December 2014; published online: 20 January 2015.
Citation: Wu X, Gong F, Yang L, Hu X, Tai F and Wang W (2015) Proteomic analysis reveals differential accumulation of small heat shock proteins and late embryogenesis abundant proteins between ABA-deficient mutant vp5 seeds and wild-type Vp5 seeds in maize. Front. Plant Sci. 5:801. doi: 10.3389/fpls.2014.00801

This article was submitted to Plant Proteomics, a section of the journal Frontiers in Plant Science.

Copyright (c) 2015 Wu, Gong, Yang, Hu, Tai and Wang. This is an open-access article distributed under the terms of the Creative Commons Attribution License (CC BY). The use, distribution or reproduction in other forums is permitted, provided the original author(s) or licensor are credited and that the original publication in this journal is cited, in accordance with accepted academic practice. No use, distribution or reproduction is permitted which does not comply with these terms. 